\title{
Is the Fundamental Science of Macroeconomics Sound?
}

\section{David Colander}

After the financial crisis of 2008, long-time critics of standard macro such as myself, temporarily gained the ear of the public. ${ }^{1}$ This led standard macro economists to respond, whereas earlier, they simply ignored us. The response has been predictable; standard economists see us critics as too hard on standard macroeconomics, claiming that we fail to understand the depth of their models and analysis. They see us criticizing earlier work, not the latest work. Those defenses worth considering agree that serious mistakes were made (Who could argue otherwise?) but place most of those mistakes on the shoulders of others, not scientific academic economists.

One of the most reasonable of those defenses was put forward by Ben Bernanke (2010). He argues that the mistakes that were made were primarily engineering or management mistakes, not mistakes in the fundamental science of macro economics, which he sees as sound. He writes "the recent financial crisis was more a failure of economic engineering and economic management than of what I have called economic science."

While I normally agree with Bernanke, and I think he did a solid job in the management of the Fed during the financial crisis, I see his success as coming despite, rather than because of, standard scientific macroeconomics. Thus, I think Bernanke is wrong in his conclusion that fundamental macroeconomic science is not to be blamed for the financial crisis. In my view, academic macroeconomics, which sees itself as doing the fundamental science of macroeconomics, is at the heart of the problem, not an innocent bystander.

My complaints about academic macroeconomics are not the same as many other critics. Specifically:

- I do not blame academic macroeconomists for abandoning the neoclassical/neoKeynesian synthesis that preceded them; I agree with modern macroeconomists; as fundamental science, that synthesis had serious problems and needed to be abandoned.

- I do not blame academic macroeconomists for failing to predict the crisis; I believe the timing of the crisis was unpredictable. I only blame them for failing to carefully explore models capable of even allowing for the crisis.

- I do not blame academic macroeconomists for using high level mathematics in their models; I blame them for the opposite-for spending far too much time dotting i's and crossing t's on a simple DSGE model,

\footnotetext{
${ }^{1}$ The piece of mine that caught on was Colander et al, 2009) Other critics whose complaints about macro were more visible after the crisis include William Buiter, (2009) and Post Keynesians such as Paul Davidson, (2009).
} 
and not creatively going far beyond it with models using much more complex mathematics and computational techniques than DSGE modelers use. $^{2}$

- I do not blame academic macroeconomists for studying models that have little relationship to the real world economy. I only blame them for not pointing out that those models should not be directly applied to policy analysis.

These complaints can be summarized into a general complaint about standard macroeconomics - it has not recognized, and still does not recognize, the limits of science and of formal modeling when studying something so complex as the macro economy. This failure to recognize, and adequately convey to policy makers the limits of our scientific understanding of the macroeconomy, has led standard macroeconomics to combine fundamental science and policy applications in ways that undermine both.

The inappropriate combination of fundamental science and policy application is not new to modern macroeconomics; modern macroeconomics has essentially followed in the path of earlier "neo" macroeconomics of combining scientific theory and policy. The difference is that modern macroeconomics emphasizes the science branch in their modeling, whereas the "neo" macro emphasized the policy branch in their modeling. But both fail because the combine the two. The "neo" policy models pretended to be fundamental scientific models, thereby giving their policy recommendations in inappropriate aura of being based on science. The "new consensus" DSGE models, which can reasonably claim to being fundamental science, allowed, and in some cases even encouraged, policy makers to believe that their DSGE models had direct relevant for policy when in fact the assumptions of the model were so far removed from reality that they had no direct relevance.

I believe that the better approach is the Classical methodological approach, and is an approach which Keynes followed as well. ${ }^{3}$ That approach strictly separated fundamental science from policy analysis. Policy did not directly follow from models; it followed from reasoned analysis which used models, but which combined models with institutional knowledge, intuition and common sense. Keynes made that approach clear when he wrote:

Economics is a science of thinking in terms of models joined to the art of choosing models which are relevant to the contemporary world. It is compelled to be this, because, unlike the typical natural science, the material to which it is applied is, in too many respects, not homogeneous through time. ... Good economists are scarce because the gift for using "vigilant observation" to choose good models, although it does not require a highly specialized intellectual technique, appears to be a very rare one. (Keynes, 1938)

\footnotetext{
${ }^{2}$ I expand on the type of complex mathematics that I believe necessary in Colander (2006) and Colander et al. (2009)

${ }^{3}$ I expand on this argument in Colander (forthcoming).
} 


\section{Searching for Policy Keys}

Probably the best way to differentiate my arguments from other critics' arguments is to provide my take of the familiar "searching for keys under the streetlight" joke. Most critics of economics use this joke to highlight the stupidity of economic theorists-by making wild assumptions they are essentially searching for policy solutions where the light is, when the policy solutions obviously lie elsewhere. That, in my view, is the wrong lesson to take from this joke. In my view, scientific economic research has no choice but to "search where the light is." You can't do science in the dark. The problem social scientists face is that because their subject matter is so complex, it is as if the social science policy keys are lost in the equivalent of almost total darkness, and you have no idea where in the darkness you lost them. This means that science and policy have to occur in different realms - one searching where there is light; the other searching in the dark.

What is stupid is if the social scientist thinks he is going to find the keys under the lamppost. Searching where the light is only makes good sense if the goal of the search is not to find the keys, but rather to understand the topography of the illuminated land, and how that lighted topography relates to the topography in the dark where the keys are lost. That, for me, is the goal of fundamental science in macroeconomics. Scientific models in macro need not have any direct policy relevance. They are potentially indirectly useful for policy because in the long run, such knowledge can be helpful in the practical search for the keys out in the dark. But they are only helpful where the topography that the people find when they search in the dark matches the topography of the lighted area being studied. But the relevance depends on "vigilant observation."

What I'm arguing is that it is most useful to think of the search for the macroeconomics policy keys as a two-part search, each of which requires a quite different set of skills and knowledge set. Pure scientific research ideally involves searching the entire illuminated domain, even those regions only dimly lit. It also involves building new lamps and lampposts to expand the topography that one can formally search. Such scientific research is often highly technical and speculative; it incorporates the latest advances in mathematical and statistical technology. Put simply, it is rocket (social) science that is concerned with understanding for the sake of understanding. Trying to draw direct practical policy conclusions from models developed in this theoretical search should be seen as a distraction to pure scientific researchers.

The policy search is something quite different. It is a search in the dark, where one thinks one has lost the keys. This policy search requires a practical sense of realworld institutions, a comprehensive knowledge of past literature, familiarity with history, and a well-tuned sense of nuance. While this search can benefit from a knowledge of what the cutting edge scientific research is telling researchers, it is based on a much broader sense of macro theory than can be captured in any one formal model. The reason is that fundamental science is guided by analytic tractability. It is relevant for policy only if the assumptions of the models match the topography for the particular policy problem one is dealing with. Given the complexity of the problems, there is no one model that can guide us, and any attempt to filter all understanding through one model, as is the case in 
modern standard macroeconomics with the new consensus DSGE model, can only cause problems. ${ }^{4}$

\section{The Relationship between Macroeconomic Science and Macroeconomic Policy}

My primary research interest is in educating economists, and what is included in the graduate core gives a good indication of what they profession believes is important. Consider the macro core course. That course does not teach students that a policy macro economist might require quite different skills and knowledge than does a fundamental scientific macroeconomist. It does not teach students that both are needed if macroeconomic science is to contribute to policy. ${ }^{5}$ I believe that is a fundamental mistake.

If science is to be helpful to policy makers, you need someone who translates the science done in the analytic light into the policy search done in the dark. It is here where I believe that the economics profession has failed society. It has not trained students in this translation role. It provides students with little formal training in the institutional knowledge vital to understanding what really happens out there, nor in the many previous explorations of policy. Instead, training in macroeconomics has focused almost exclusively on technical training in a particular model that framed the macroeconomic problem in a highly stylized fashion. It was as if one took one particular lighted area and told all researchers that they had to discuss policy in reference to this topography, even when it was clear that the topography we were finding out in the dark was fundamentally different than the topography illuminated by that model. The almost sole focus on the DSGE model meant that scientific macro researchers were of almost no help in preparing for, or dealing with, the financial crisis. Because they were guiding people from a model that assumed people were on a smooth terrain when in fact the real world terrain was full of cliffs, they did more harm than good, and contributed to the economy falling off a cliff.

In his speech, a second argument Bernanke gives in support of his argument that macroeconomic scientists have not failed society, is that while DSGE modelers had not taking into account credit problems, earlier economists had. He states "the fact that dependence on unstable short-term funding could lead to runs is hardly news to economists; it has been a central issue in monetary economics since Henry Thornton and Walter Bagehot wrote about the question in the 19th century." I find this justification very strange. In my view, the fact that Thornton and Bagehot provided useful insights into macroeconomic policy problems is an indictment of fundamental macroeconomic science as currently conceived. If it were fundamental science, it would be taught somewhere-ideally in the core macro courses. That doesn't happen. The core

\footnotetext{
${ }^{4}$ Good scientists recognize these limitations. For example, Robert Lucas noted the limitations of DSGE models for understanding depressions and credit crises long before the crisis occurred. He wrote "there's a residue of things they (DSGE models) don't let us think about. They don't let us think about the U.S. experience in the 1930's or about financial crises and their real consequences in Asian and Latin America; they don't let us think very well about Japan in the 1990's." (Lucas, 2004) But that acknowledgement did not lead to standard macroeconomists to develop an active research program studying such issues, as I believe should have happened. Instead, they were silent when others argued that all macroeconomics should be done through a DSGE lens. (Chari and Kehoe, 2006).

${ }^{5}$ Some economists have skills in both areas. Robert Solow comes to mind. But most economists have a comparative advantage in one or the other, making specialization and trade advantageous.
} 
macroeconomic courses teach DSGE modeling almost exclusively. Not only are the writings of Thornton or Bagehot missing, the writings of Keynes, Minsky, Hicks, Clower, Leijonhufvud, Gurley, Davidson, Leijonhufvud, Goodhardt, Clower, or even Friedman, to mention just a few of those whose writings could also have contributed to a better understanding of the crisis, are missing as well. Most students who have graduated in the past twenty years would never have even heard of half of them, let alone read them. If nobody reads them, and their ideas aren't part of the material that students study or learn, how can Bernanke consider them part of modern economic science?

Let me be clear about what I am saying. If the economics profession took advantage of specialization, I would have no problem in training a small group fundamental macroeconomic scientists in the techniques needed to formally model a macro economy. That training would be much more high level than it currently is, and would involve training in nonlinear dynamics and complex systems analysis. It would be rocket science. But that training would be supplemented by the training of a larger group of macro policy analysts in the broader cannon of macroeconomics - the knowledge of ideas, institutions, and past policy successes and failures, that economists have gathered from past experience. The two groups would interact, and the result would be a much richer and more diverse set of models, and a more diverse set of macroeconomists, than we currently have.

\section{Bernanke's Fundamental Mistake}

My final objection to the arguments Bernanke puts forward relates to the role that we should give what Michael Woodford (2009) has called the new consensus model. By new consensus he means the New Keynesian modified DSGE model that dominates standard macro today. Reflecting New Consensus policy macroeconomist's views, Bernanke seems comfortable with this New Consensus approach, which essentially involves filtering all macro analysis through a DSGE-type New Consensus model, and using insights from that filtered model to guide policy in normal times. He does this because he sees models as a necessary underpinning of policy. He writes "Underpinning any practical scientific or engineering endeavor, such as a moon shot, a heart transplant, or the construction of a skyscraper are: first, fundamental scientific knowledge; second, principles of design and engineering, derived from experience and the application of fundamental knowledge; and third, the management of the particular endeavor... Success in any practical undertaking requires all three components." He then goes on to make the argument that I discussed above - that the fundamental science of macro is sound, and that the crisis reflects problems of engineering and science.

I do not find the current "New Consensus" model an appropriate foundation for policy. The reason is that if a model doesn't include abnormal times as a special case of normal time, and provides no way of distinguishing normal times from abnormal times, then the model cannot serve as your fundamental scientific model. If that is the best model one has, it is best to admit that one doesn't have a firm scientific understanding of what is going on, and to give up the pretense of fundamental science. You can still have models, but those models developed under the streetlight have to be judged by their intuitive relevance. Do the fit the topography of the search for the policy keys in the dark. 
In my view, before we have anything approaching a intuitively satisfying model we need to include in the models three aspects that current DSGE models do not. The first is radical uncertainty; the second is the strategic interactions of large numbers of heterogeneous agents that creates multiple levels of strategic interaction, and the third is the a reasonable story about stability, explaining how the layers and layers of institutional detail relate to the structural stability of our macroeconomy. ${ }^{6}$ The third issue becomes important because any simple model with radical uncertainty and strategic interaction should be wildly unstable, but our economy isn't, and the likely explanation involves institutions.

Currently the New Consensus models don't come close to dealing with any of these three issues. Yes, with sufficient ad hoc adjustments to a DSGE model, researchers have been able to make a model that "fits the data," but fitting the data does not make the model intuitive satisfying. With sufficient ad hoc adjustments, one can make any model fit the data. ${ }^{7}$

\section{Policy with a Healthy Skepticism of Formal Models}

Given the complexity of the macro economy, the most honest statement about macro theory is that we have no fundamental scientific macro theory. We are in what Schumpeter called the pre-scientific (but not pre-analytic) stage of scientific development of macroeconomics. We have some interesting formal models, we also have what might be called the macroeconomic cannon - the collective experience and the insights of previous economists who have written about that experience. That cannon, not some untestable fundamental science, should, in my view, be a central part of what students of macroeconomics learn.

I can hear standard macroeconomists complaining that teaching students that cannon will mean that they won't really learn fundamental macroeconomic science. My answer to that concern is "that's right, but it is not much of a loss." My view is that, contrary to what Bernanke suggests in his above quotation, policy does not need an underlying science; policy can precede science.

An analogy can be made to the building cathedrals in the middle ages. Builders didn't have formal scientific knowledge that followed from models; they had practical knowledge of what worked, and what didn't. Each new cathedral would push the envelope a bit further, until it crashed. Then the master masons would study the reasons for the crash and build that understanding into their working knowledge and rules of thumb. Policy analysis in macro should proceed in the same way.

\footnotetext{
${ }^{6} \mathrm{I}$ have discussed the importance of these issues in my discussion of Post Walrasian macroeconomics (Colander, 1996, 2006) See also Colander (2010)

${ }^{7}$ On this issue, I fully agree with the strong DSGE modelers, such as Chari, Kehoe and McGratten (2009) who argue that the New Keynesian ad hoc adjustments to the model do not make it policy useful. Where I disagree with them is that I don't see their DSGE models as directly policy relevant either, whereas they do.
} 
My attitude toward fundamental theory can be seen in my version of another joke that standard economists tell. In this joke, a physicist, an engineer, and an economist are given a stopwatch, a string, and a ball, and told that the person who can best measure the height of a building will get into a Scientific Hall of Fame. The physicist ties the ball to the string, hangs it down from the roof, and, using the stopwatch, and calculates the length of time it takes the pendulum to swing from side to side. From that information, he estimates the height of the building. The engineer takes the ball and drops it off the top. He then uses the stopwatch to determine how long the ball takes to fall, and estimates the height of the building accordingly. In the standard economist's telling of this joke, it is the economist who wins the place in the Scientific Hall of Fame by taking the stopwatch, trading it with a guard in the building for the building plans, and simply reading the height of the building from the blueprints.

This joke conveys the way standard macro economists think of theory and models. It underlies Bernanke's justification of fundamental macro science. He recognizes that it has serious problems, but it is the only formal blueprints we have. Since formal blueprints are necessary, we have to use them.

I see the macroeconomic problem differently. In my version of this joke, the economist loses. The reason why is that in the building process, the builders continually adjusted the plans, creating the gerrymandered system that is our economy. They created a variety of different blueprints, replacing one set with another, and they never marked down their adjustments on the blueprints. So the standard economist reading from the blueprints got the wrong answer. They end up not exploring the entire lighted area, and providing the wrong guidance for those searching for the policy keys.

My suggestion is that macroeconomists should give up the obsession with macroeconomic theory - and trade the blueprints for the stopwatch, string, and ball, and concentrate on creative ways of using the tools they have to shed light on a wide variety of topographies. We should admit that we don't have the truth, or even a model that comes close to the truth. In policy analysis of a complex system, such as the macro economy, the best policy makers can do is look at various blueprints, but not see any as the correct ones, and combine the insights they get from those blueprints with a solid knowledge of history, history of ideas, and macroeconomic institutions. Combined they have the best chance at muddling through. ${ }^{8}$

\footnotetext{
${ }^{8}$ Let me be clear. The argument I am presenting here is not an argument against modeling or theorizing. It is simply an argument against a worship of grand theorizing and of drawing direct policy conclusions from highly abstract models. It suggests that the most useful macro models will likely be those that are narrow in scope and are designed to answer particular questions about some sub issue in macro. My suggestion is that the focus should be on designing models that shed light on some small problem that may be useful in taking the next step on the mountain, while keeping the broad theoretical blueprints in the back of one's mind to be referred to when it seems intuitively appropriate to do so.
} 


\section{Bibliography}

Bernanke, Ben. 2010. "Implications of the Financial Crisis for Economics" Princeton University Speech.

http://www.federalreserve.gov/newsevents/speech/bernanke20100924a.htm,

September 24

Buiter, William. 2009. "The unfortunate uselessness of most 'state of the art' academic monetary economics" Maverecon February 3

http://www.voxeu.org/index.php?q=node/3210

Chari, V.V., and P. Kehoe, 2006. Modern macroeconomics in practice: How theory is shaping policy. Journal of Economic Perspectives 20(4), 3-28.

Chari, V.V., P. Kehoe and E. McGrattan, 2009. "New Keynesian Models: Not Yet Useful for Policy Analysis" Macroeconomics, (AEA) vol 1. No. 1

Colander et al. 2009. "The Dahlem Report: The Financial Crisis and the Systemic Failure of Academic Economics" http://www.debtdeflation.com/blogs/wpcontent/uploads/papers/Dahlem_Report_EconCrisis021809.pdf

Colander, David, Peter Howitt, Alan Kirman, Axel Leijonhufvud, and Perry Mehrling, 2008. "Beyond DSGE Models: Toward an Empirically Based Macroeconomics" American Economic Review, 98:2, 236-24.

Colander, David, 1996. (ed.) Beyond Microfoundations: Post Walrasian Economics, Cambridge, UK. Cambridge University Press.

Colander, David, 2006. (ed.) Post Walrasian Macroeconomics: Beyond the Dynamic Stochastic General Equilibrium Model, Cambridge, UK. Cambridge University Press.

Davidson, Paul. 2009. The Keynes Solution The Path to Global Economic Prosperity Palgrave Macmillan, September 2009

Keynes, J.M. 1938. Letter to Roy Harrod. 4, July. http://economia.unipv.it/harrod/edition/editionstuff/rfh.346.htm

Lucas, Robert, 2004. "My Keynesian Education” in M. De Vroey and K. Hoover (eds.) The IS'LM Model: Its rise, Fall and Strange Persistence, Annual Supplement to Vol. 36 of History of Political Economy, Durham, NC, Duke University Press

Woodford, Michael. 2009. "Convergence in Macroeconomics: Elements of the New Synthesis" American Economic Journal: Macroeconomics 2009, 1:1, 267-279 
Is the Fundamental Science of Macroeconomics Sound?

\section{Framing the Macro Debate}

\section{David Colander}

Paper prepared for the ASSA Meetings, Jan , 2011 